\title{
Pathways for advancing the scholarship on transformation towards a sustainable and equitable community
}

\section{Introduction}

Organizations operate in a complex context that is shaped by demographic, political, ecological, social, technological and ethical forces. Organizations must undertake "intertemporal trade-offs to achieve intergenerational equity" (Bansal and DesJardine, 2014), which, when combined with the triple bottom line concept, means balancing financial goals with environmental conservation and social equality (Elkington, 1994). Because most contemporary paradigms prioritize economic imperatives and regard larger contexts as "garnishing on the plate," integrative approaches remain "the roads less travelled." By viewing the world from fresh perspectives and reexamining old beliefs, we may be able to create a future that does not promote the nature-culture divide that has harmed billions globally (Banerjee, 1999). It may pave the way for a more sustainable and inclusive approach to organizational management that balances financial objectives with wider considerations. The sustainability issues should push companies to consider boundaries in a larger context when doing stakeholder analysis.

It is essential to examine how stakeholders in different parts of the world conceptualize and implement organizational sustainability. This comparison study is likely to produce some intriguing results. For example, in the context of micro-, small and medium enterprises, there is the view that "the third world reality constructed by this Eurocentric corporate social responsibility, silences and/or denies the possibility of existence of alternate trajectories of fulfilling business responsibility and ensuring welfare" (Jammulamadaka, 2015, p.79) and that "the 'rational' management of resources is integral to the Western economy, and its imposition on developing countries is problematic" (Banerjee, 2003, p. 143).

Transformations are not necessarily linear and often pose multiple challenges. For example, "social transformations entail more plural, emergent, and unruly political realignments, concerning social and technological innovations driven by diversely incommensurable knowledge, challenging incumbent structures and pursuing contending (even unknown) ends" (Stirling, 2014). Apart from businesses, it is essential to study how individuals and local communities collaborate to strengthen their economic, social and environmental standing.

While the debate over conceptual issues and the dimensions of the sustainability paradigm continues, it is important to identify and appreciate the practical components of organizational sustainability at the micro- and macro-levels (Jain et al., 2019; Sharma and Mahendru, 2017; Talan and Sharma, 2019). Sustaining an organization requires a long-term perspective, with an emphasis on environmental management, green technology, social equity and inclusion. Socially sustainable organizations bring value to the communities in which they operate by increasing their partners' human capital and enhancing the social capital of the communities in which they operate (Dyllick and Hockerts, 2002). Numerous unsustainable behaviors have their origins in economic disparity and social injustice. Developing a culture that values diversity and inclusiveness, as well as accepting a range of unorthodox approaches to subjective well-being at work and beyond, is essential for creating

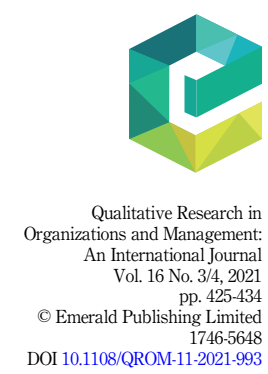


QROM

$16,3 / 4$

social justice both within and beyond the organization (Boiral et al., 2018). Employee proenvironmental behavior, for example, is essential to the organization's environmental programs' efficacy (Boiral et al., 2015).

Corporate governance aims to achieve a balance between an organization's economic and social objectives through power accountability, resource efficiency and social behavior (Bansal et al., 2021; Sethi, 2002). There is a link between effective governance and sustainability (Aras and Crowther, 2008; Talan and Sharma, 2020). Collaborations across sectors in sustainability initiatives, including businesses, nonprofits and governments, need to study how to maximize the potential of such collaborations.

Numerous studies on various elements of organizational sustainability are being conducted, the majority of which employ quantitative methodologies. There is, however, skepticism regarding the extent to which organizations have moved toward real sustainability. Certain concerns and difficulties appear to be slipping through these quantitative approaches' seams. More incisive and subjective techniques are required, since they will generate more useful insights that will aid joint efforts to achieve sustainability across cultures, geographies and demographics. We are glad to present this special issue (SI) of qualitative research in organizations and management, themed "The roads less Travelled: Transformation Towards a Sustainable and Equitable Community". The issue focuses on research in a variety of disciplines related to sustainability, taking into account a variety of methodologies as well as the attitudes, experiences and learnings of key stakeholders.

\section{Contributions of this special issue}

In "Zebras showing their stripes: a critical sense-making study of women CSR leaders", Cherneski (2021) presents the findings from interviews with nine senior female corporate social responsibility (CSR) leaders. These leaders oppose both overt and subtle gendered norms in their organizations. By destabilizing prescribed "truths," questioning dominant discourses and adding rival discourses, these women are upsetting some of the traditions and understandings that many scholars feel are responsible for (re)forming gendered institutions. They are like zebras who do not mind showing their stripes, since their thoughts and reflections push others to rethink what is possible.

Dhanda and Shrotryia (2021) review the extant literature on organizational sustainability. Their paper "Corporate sustainability: the new organizational reality" integrates previous research in the area and offers a conceptual framework for corporate sustainability and sustainable business models. It examines the progress of firms towards sustainability and how the context of sustainability has changed over time. The study examines how firms have changed their focus from enforcement and philanthropy to achieving a sustainability edge, as well as the transformation from traditional to sustainable business models. The study identifies gaps that should lay the groundwork for future corporate sustainability research.

In "Hard/heart worker: work intensification in purpose-driven organizations", Dupret and Pultz (2021) investigate how purpose-driven businesses with a sustainability emphasis could include internal social sustainability to align outward mission with employee well-being. The study suggests that organizations' search for (sustainable) meaning is inextricably linked to the recognition of employees as resourceful and intrinsically valuable human beings. The study suggests that, in some cases, working for organizational sustainability can create challenges that can reduce employee well-being because it entails continuous negotiation of the limits between paid work and leisure time, meaning and job commitment, selfmanagement and work intensification.

In "Social entrepreneurship for scalable solutions addressing sustainable development goals (SDGs) at BoP in India", Goyal et al. (2021) have explored how social enterprises provide highquality public services at the bottom of the pyramid while also addressing the SDGs. 
The study proposes a conceptual framework, comprising three methods for a social enterprise to address institutional voids and SDGs at the bottom of the pyramid while maintaining the scalability and reach of social entrepreneurship solutions and services. These methods include technology, especially Internet of Things (IoT) and cloud infrastructure, to collect data on services and solutions automatically, lowering maintenance costs, avoiding task drift and improving quality. Digitalization also aids in the establishment of processes and their replication at lower costs. The second approach refers to the need for emphasis on the 4As (awareness, accessibility, availability and affordability) as aids in the scaling of the social enterprise. The third approach refers to multisector stakeholder alliances and collaborations that aid in the success of the social enterprise.

In "Study of sustainability issues in an Indian logistics service provider: SAP-LAP approach", Gupta and Singh (2021) have examined issues such as environmental concerns, the necessity for CSR initiatives, the transformation of manual procedures into green processes, reframing resources and processes into sustainable assets, and organizational performance measurements. Using a case-study approach, the paper indicates that green practices have a positive impact on the performance of logistics service providers (LSPs). The study also suggests that the adoption of sustainable practices by LSPs can result in sustainable performance. To meet market needs, LSPs could utilize a sustainability index to measure their sustainability performance.

The paper "Promoting sustainable palm oil in supply chain strategy: a food business case study" by Kasim et al. (2021) demonstrates the challenges associated with the implementation of sustainability strategy in supply chains for a contentious product like palm oil. The goal of the study is to improve company-level understanding of sustainable palm oil strategy and to close the gap between strategy formulation and implementation. The significant motivator for taking action on environmental and social sustainability issues is external pressure. Furthermore, designing and executing sustainable palm oil supply chain strategies requires effective coordination and collaboration across multiple sectors.

In "Financial well-being for a sustainable society: a road less travelled", Mahendru (2020) proposes an organizing framework based on a review of the extant literature. Financial literacy and capability programs, for example, are crucial in reinforcing both objective and subjective components of financial well-being. Financial education has a minimal impact on changing financial behavior, according to the literature. Financial capability plays an essential but insufficient role in improving literacy. The understanding of financial literacy and capacity can help people improve their financial well-being. As a result, investigating this relationship can aid researchers in determining how financially capable individuals may contribute to an institution's financial success, while assisting research when producing and marketing their products. Continuing the discussion, financial well-being is said to be the outcome of three aspects: financial capability, financial literacy and psychological factors.

Using in-depth interviews, Rankin (2021), in "Under pressure: exploring pressures for corporate social responsibility in mutual funds", examines organizational conformance and differentiation in two types of organizations: socially responsible investment (SRI) and nonSRI businesses. In the context of CSR, the study examines as to how mutual fund companies interpret competing pressures to comply or differentiate. The findings suggest that, while both types of companies use CSR to comply with regulations, SRI companies are far more likely than non-SRI companies to use CSR to differentiate and set themselves apart from competitors. Missions that stress doing good as well as creating income frequently incorporate CSR into the identity of SRI firms. Non-SRI companies place a higher value on stakeholders and minimize the usage of CSR as a source of innovation or competitive advantage. 
QROM

$16,3 / 4$

428
In "Integrated sustainable supply chain management and firm performance in the Indian textile industry", Shahi et al. (2021) explore the link between sustainable supply chain management (SSCM) practices in the Indian textile industry and business performance. The study concludes that an integrated approach to SSCM activities improves firm productivity, revenues and net profit. The idea that investing in SSCM procedures increases expenses and lowers income is incorrect. The authors recommend that Indian textile businesses should follow and foster a more constructive and integrated SSCM approach.

In the context of renewable energy, Walker et al. (2021) in "Non-indigenous partner perspectives on indigenous peoples' involvement in renewable energy: exploring reconciliation as relationships of accountability or status quo innocence?' have explored how renewable energy collaborations can help Canada transcend its colonial history and present by gaining a better understanding of how non-Indigenous people employed in the sector interact with their Indigenous counterparts. The authors conclude that, despite the government's efforts, little progress appears to have been accomplished in Canada's renewable energy market. The participants in the study believed that there was a need for reconciliation measures on occasion because they had been formed by settler colonialism. However, these almost always fell short of actual reform in the larger businesses or utility practices. Perhaps more federal laws or sanctions for non-Indigenous partners, led by Indigenous governments, are needed.

Table 1 summarizes the papers published in this SI and proposes a relationship between the research areas addressed therein and the related United Nations Sustainable Development Goals (SDGs).

\subsection{Research opportunities}

To understand the current state of scholarship in the field of this SI, we conduct a thematic analysis employing the keywords used by the papers included in this SI. A SCOPUS search, using the keywords of the papers included in this SI, leads us to 472 papers, out of which 149 papers are removed manually after reading their abstracts. The remaining 323 papers are analyzed through "bibliometrix" package of "R" software. The thematic map emerging from this analysis (Figure 1) guides us to the current state of knowledge in this field. The quadrants indicate four types of themes - motor theme (upper right), peripheral/niche theme (upper left), emerging/disappearing theme (lower left) and general/basic theme (lower right) (Bamel et al., 2020; Rodríguez-Soler et al., 2020). Centrality refers to the degree of interaction and relevance amongst the themes. Density refers to the strength and development of internal ties within a theme (Aparicio et al., 2019).

Several of the papers appearing in this SI belong to the quadrant of basic themes. Four themes, namely Sustainability (relates to the triple bottom line, industrial ecology, management, well-being, governance), Sustainable development (sustainable society index, innovation, composite indicators, consumption, environment(/al) management, human resource management, indicators), Sustainable society (marketing, resilience, risk, sharing, strategy/ practice, sustainable organizing), Leadership (work intensification, sustainable organizational performance, capacity building, innovative work behavior, organizational learning, change) and Green chemistry (energy, ethics, vision, green practices) fall under the basic theme, listed according to their bubble size (descending order of frequency of occurrences). These themes are very important to this concerned field, implying that they might have less relevance but it is much developed over the years. Mahendru (2020) and Dupret and Pultz (2021) researched on financial and employee well-being, respectively. Gupta and Singh (2021) and Shahi et al. (2021) involve green practices and organizational performance.

Themes such as "Innovation" (relate to public health, environment, behavior, Covid-19), "Development" (climate change and collaboration) and "Organization" (CSR-related activities) belong to the motor quadrant implying that the centrality and density of themes are both high 


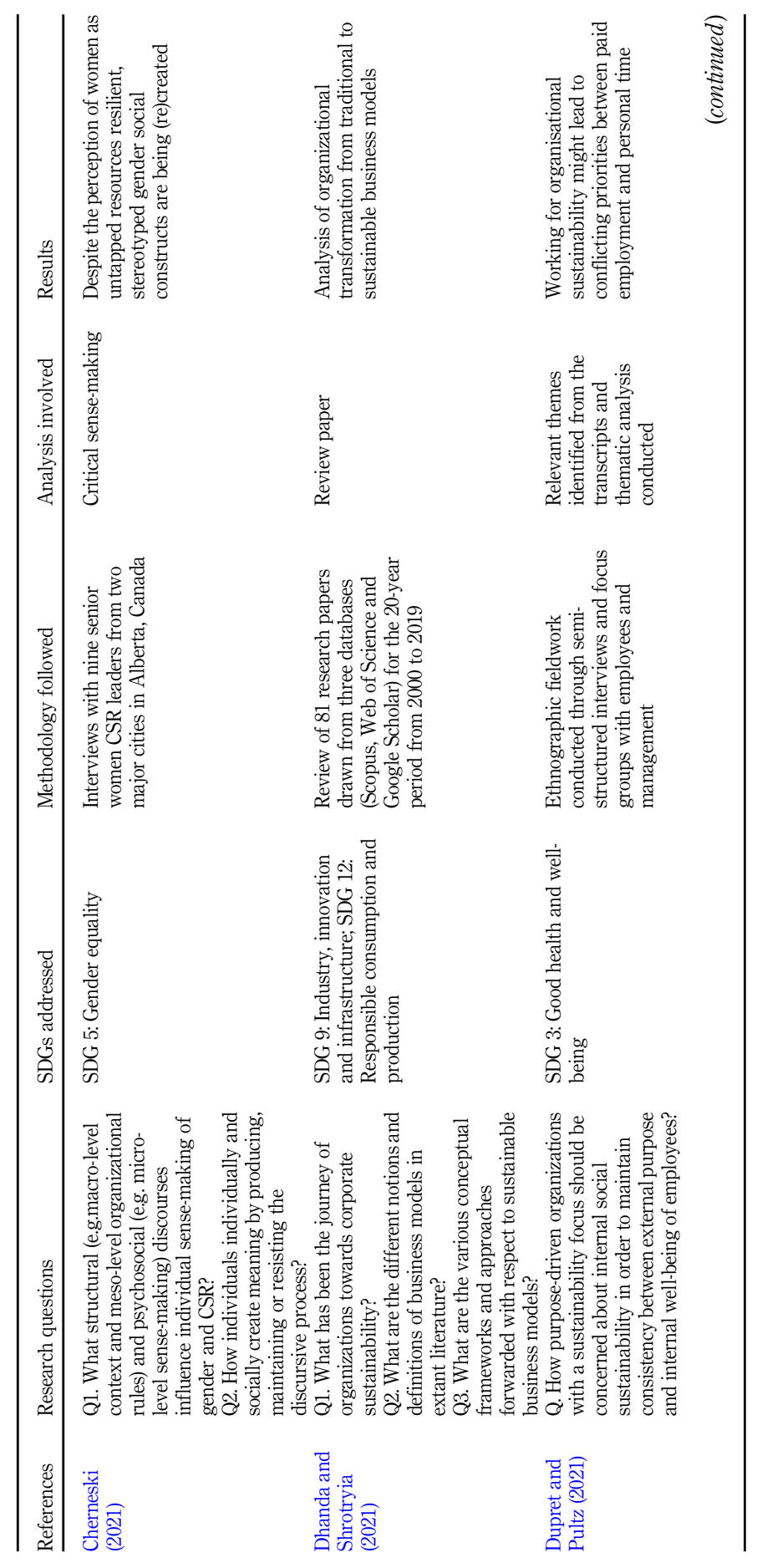

Editorial

429

Table 1. Summary of papers in the SI 


\section{QROM $16,3 / 4$}

\section{0}

Table 1.
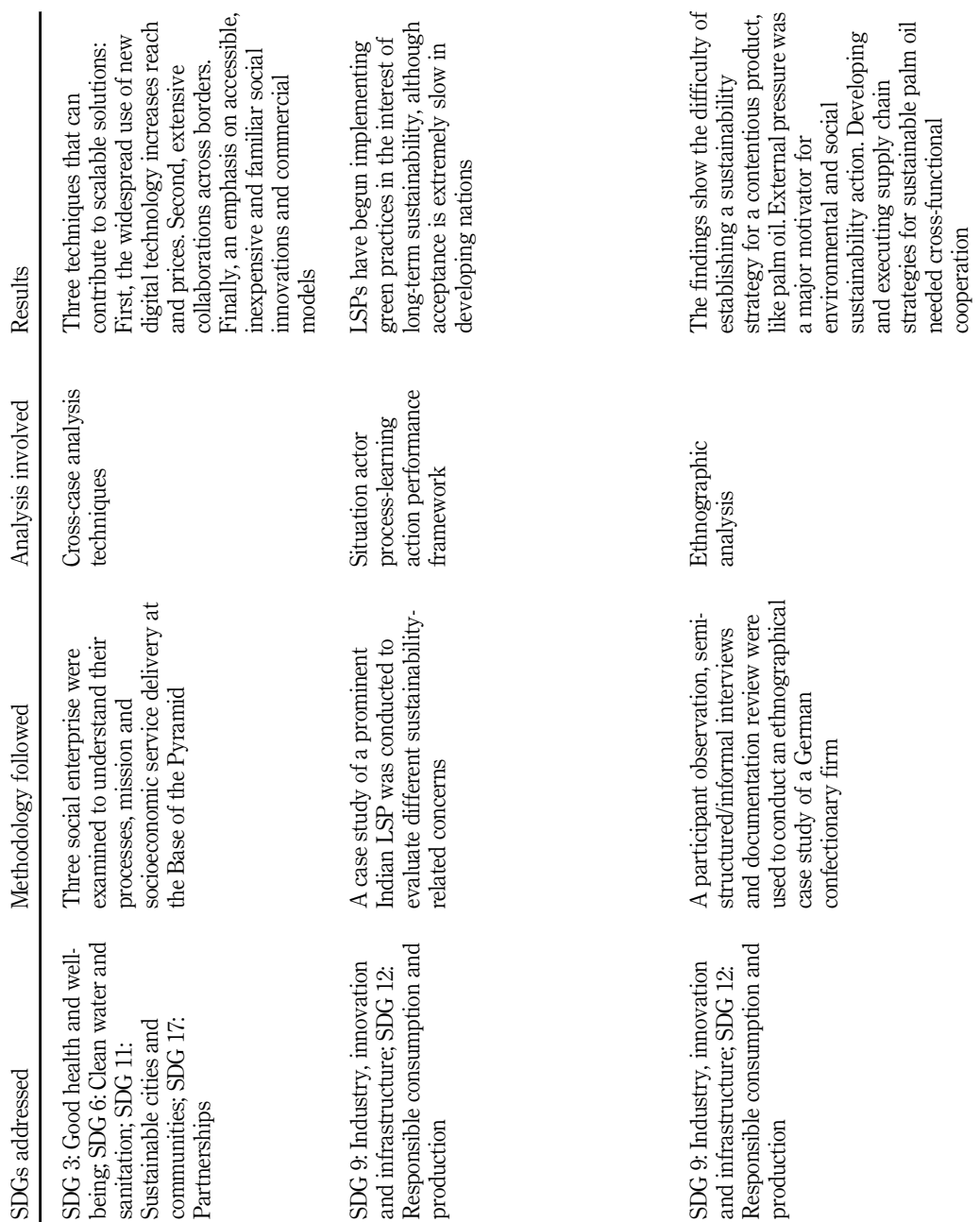

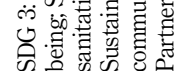

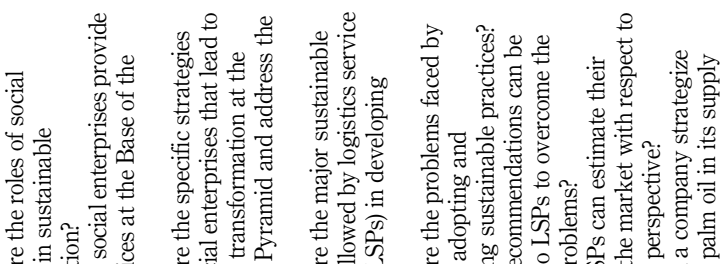

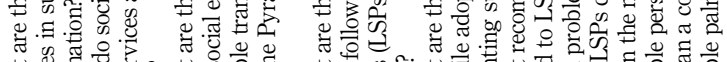

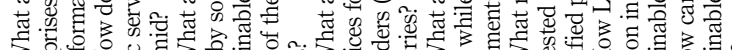

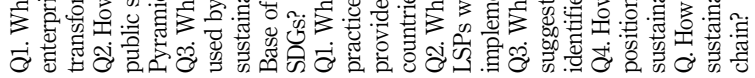

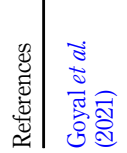

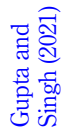

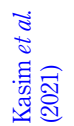




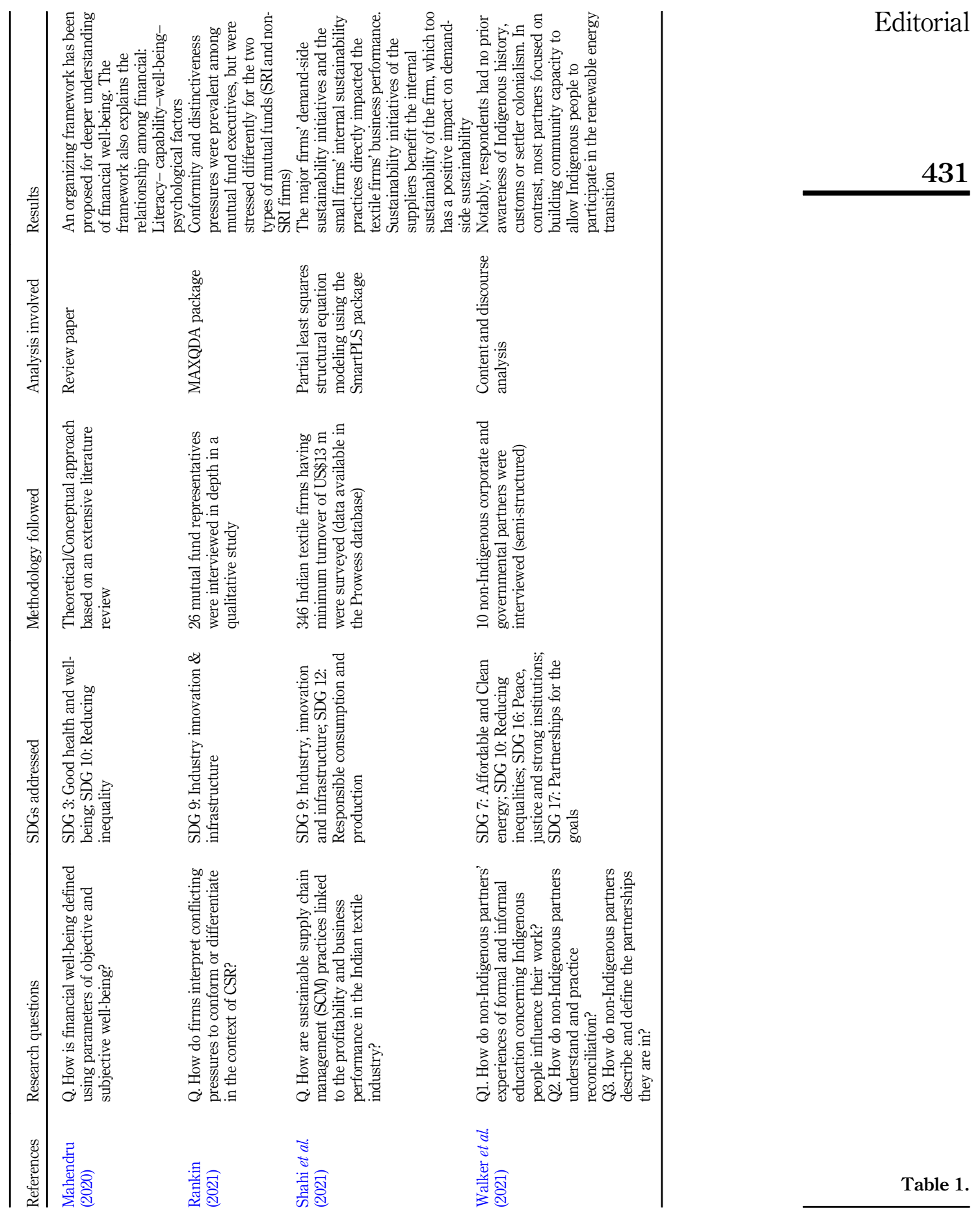




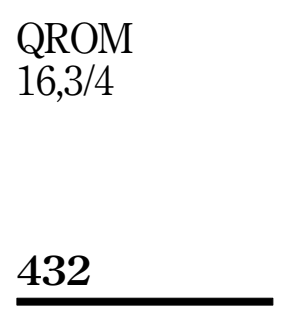

Figure 1.

Thematic map of the scholarship in the related areas

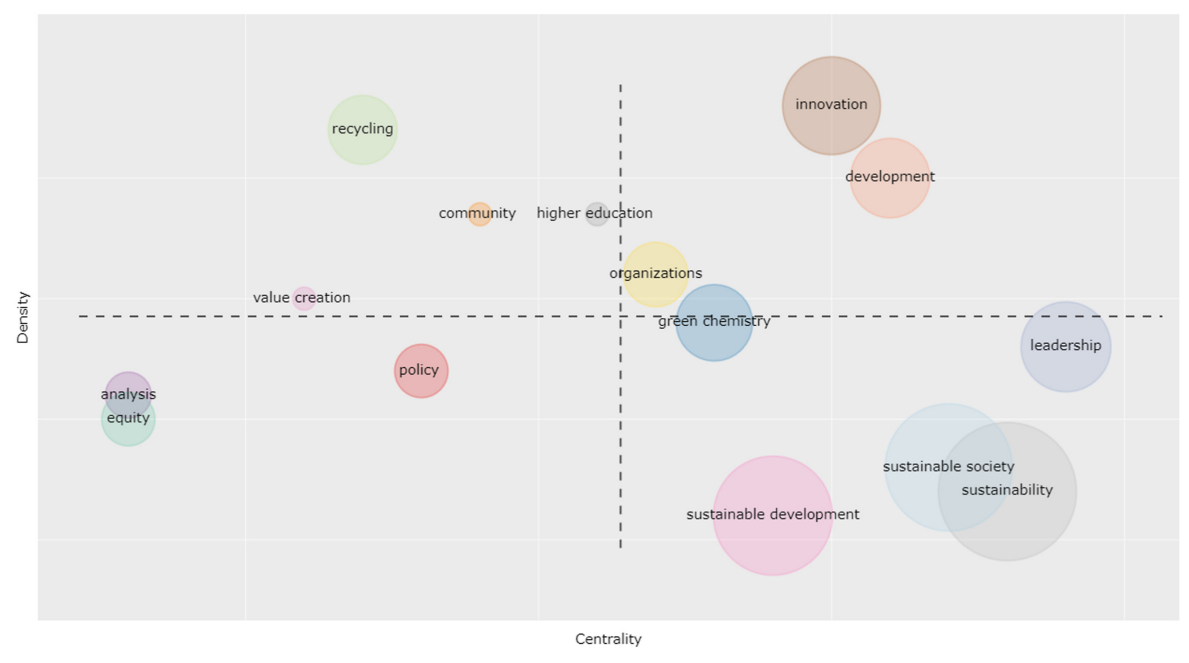

with "Innovation" having the highest centrality amongst all the themes. Green chemistry (energy, ethics, vision, green practices) falls partly in this quadrant and partly in the basic themes quadrant.

Recycling (relates specifically to industries and emissions), Value creation, Community and Higher education are niche themes that have less development and more relevance with "Recycling" having the highest centrality. Walker et al. (2021) address the themes of education and community building.

"Policy", "Equity" and "Analysis" fall in emerging themes with low density and low centrality, implying further directions to the research in this field.

Nudged by the papers in this SI, we identify a number of research opportunities and approaches in an emerging and rapidly developing field, which can be the subject of further investigation. These include

(1) To examine and compare the sustainability effectiveness of LSPs by using sustainability index.

(2) To further study failed social enterprises and understand the challenges they need to overcome for making a contribution to the achievement of SDGs.

(3) To empirically test CSR behaviors along with CSR signals of SRI and non-SRI firms.

(4) To further examine the reconciliation, decolonization, Indigenous rights and selfdetermination and related challenges amongst native communities in various environments and industries.

(5) To further investigate factors and the processes of creating and implementing sustainable supply chain strategies and addressing challenges, such as addressing evolving customer needs and the imperatives of cost efficiency

(6) To identify and examine personality traits, psychological and cognitive skills, and other objective and subjective factors which influence financial well-being and how these vary across developed/developing nations.

The SI encompasses diverse research directions, methodologies and perspectives cutting across international research boundaries. We purposefully broadened the range of 
methodological approaches by including conceptual, empirical, analytical and review articles. We hope that the issue will help advance this rapidly growing area of academic research and help organizations, policy makers and individual stakeholders to take more informed decisions in the collective progress towards a more equitable and sustainable world.

\section{Gagan Deep Sharma and Meenakshi Handa University School of Management Studies, Guru Gobind Singh Indraprastha University, New Delhi, India}

\section{References}

Aparicio, G., Iturralde, T. and Maseda, A. (2019), "Conceptual structure and perspectives on entrepreneurship education research: a bibliometric review", European Research on Management and Business Economics, Vol. 25 No. 3, pp. 105-113.

Aras, G. and Crowther, D. (2008), "Governance and sustainability: an investigation into the relationship between corporate governance and corporate sustainability", Management Decision, Vol. 46 No. 3, pp. 433-448.

Bamel, U., Pereira, V., Del Giudice, M. and Temouri, Y. (2020), "The extent and impact of intellectual capital research: a two decade analysis", Journal of Intellectual Capital. doi: 10.1108/JIC-05-2020-0142.

Banerjee, S.B. (1999), "Sustainable development and the reinvention of nature", Critical Management Studies Conference, Environment Stream, Manchester, UK.

Banerjee, S.B. (2003), "Who sustains whose development? Sustainable development and the reinvention of nature", Organization Studies, Vol. 24 No. 1, pp. 143-180.

Bansal, P. and DesJardine, M.R. (2014), "Business sustainability: it is about time", Strategic Organization, Vol. 12 No. 1, pp. 70-78.

Bansal, S., Sharma, G.D., Rahman, M.M., Yadav, A. and Garg, I. (2021), "Nexus between environmental, social and economic development in South Asia: evidence from econometric models", Heliyon, Vol. 7 No. 1, doi: 10.1016/j.heliyon.2021.e05965.

Boiral, O., Paillé, P. and Raineri, N. (2015), “The nature of employees' pro- environmental behaviors", Disputatio, pp. 45-66.

Boiral, O., Raineri, N. and Talbot, D. (2018), "Managers' citizenship behaviors for the environment: a developmental perspective", Journal of Business Ethics, Springer Netherlands, Vol. 149 No. 2, pp. 395-409.

Cherneski, J. (2021), "Zebras showing their stripes: a critical sense-making study of women CSR leaders", Qualitative Research In Organizations and Management: An International Journal, Vol. 16 Nos 3/4, pp. 435-463. doi: 10.1108/QROM-07-2020-1984.

Dhanda, U. and Shrotryia, V.K. (2021), "Corporate sustainability: the new organizational reality", Qualitative Research In Organizations and Management: An International Journal, Vol. 16 Nos 3/4, pp. 464-487. doi: 10.1108/QROM-01-2020-1886.

Dupret, K. and Pultz, S. (2021), "Hard/heart worker: work intensification in purpose-driven organizations", Qualitative Research In Organizations and Management: An International Journal, Vol. 16 Nos 3/4, pp. 488-508. doi: 10.1108/QROM-07-2020-1989.

Dyllick, T. and Hockerts, K. (2002), "Beyond the business case for corporate sustainability", Business Strategy and the Environment, Vol. 11 No. 2, pp. 130-141.

Elkington, J. (1994), "Towards the sustainable corporation: win-win-win business strategies for sustainable development”, California Management Review, Vol. 36 No. 2, pp. 90-100.

Goyal, S., Agrawal, A. and Sergi, B.S. (2021), "Social entrepreneurship for scalable solutions addressing sustainable development goals (SDGs) at $\mathrm{BoP}$ in India”, Qualitative Research In Organizations and Management: An International Journal, Vol. 16 Nos 3/4, pp. 509-529. doi: 10.1108/QROM-07-2020-1992. 
QROM $16,3 / 4$
Gupta, A. and Singh, R.K. (2021), "Study of sustainability issues in an Indian logistics service provider: SAP-LAP approach", Qualitative Research In Organizations and Management: An International Journal, Vol. 16 Nos 3/4, pp. 530-549. doi: 10.1108/QROM-02-2020-1897.

Jain, M., Sharma, G.D. and Mahendru, M. (2019), "Can I sustain my happiness? A review, critique and research agenda for economics of happiness", Sustainability (Switzerland), Vol. 11 No. 22, p. 6375 .

Jammulamadaka, N. (2015), "Responsibility for the third world factory: limits of eurocentric CSR and making room for the state", Decision, Vol. 42 No. 1, pp. 71-82.

Kasim, E., Stöhr, J. and Herzig, C. (2021), "Promoting sustainable palm oil in supply chain strategy: a food business case study", Qualitative Research In Organizations and Management: An International Journal, Vol. 16 Nos 3/4, pp. 550-571. doi: 10.1108/QROM-03-2020-1907.

Mahendru, M. (2020), "Financial well-being for a sustainable society: a road less travelled", Qualitative Research In Organizations and Management: An International Journal, Vol. 16 Nos 3/4, pp. 572-593. doi: 10.1108/QROM-03-2020-1910.

Rankin, C.P. (2021), "Under pressure: exploring pressures for corporate social responsibility in mutual funds", Qualitative Research In Organizations and Management: An International Journal, Vol. 16 Nos 3/4, pp. 594-613. doi: 10.1108/QROM-07-2020-2000.

Rodríguez-Soler, R., Uribe-Toril, J. and De Pablo Valenciano, J. (2020), "Worldwide trends in the scientific production on rural depopulation, a bibliometric analysis using bibliometrix R-tool", Land Use Policy, Vol. 97, p. 104787.

Sethi, S.P. (2002), "Standards for corporate conduct in the international arena: challenges and opportunities for multinational corporations", Business and Society Review, Vol. 107 No. 1, p. 20.

Shahi, S.K., Shiva, A. and Dia, M. (2021), "Integrated sustainable supply chain management and firm performance in the Indian textile industry", Qualitative Research In Organizations and Management: An International Journal, Vol. 16 Nos 3/4, pp. 614-635. doi: 10.1108/QROM-032020-1904.

Sharma, G.D. and Mahendru, M. (2017), "Thirst for a new management theory”, Asian Journal of Management, Vol. 8 No. 3, p. 921.

Sterling, A. (2014), Emancipating Transformations: from Controlling 'the Transition' to Culturing Plural Radical Progress, No. 64, Brighton and Hove.

Talan, G. and Sharma, G.D. (2019), "Doing well by doing good: a systematic review and research agenda for sustainable investment”, Sustainability (Switzerland), Vol. 11 No. 2, p. 353.

Talan, G. and Sharma, G.D. (2020), "From business goals to societal goals via sustainable investment: an integrative review and research agenda", World Review of Entrepreneurship, Management and Sustainable Development, Vol. 16 No. 1, pp. 108-124.

Walker, C.J.R., Doucette, M.B., Rotz, S., Lewis, D., Neufeld, H.T. and Castleden, H. (2021), "NonIndigenous partner perspectives on Indigenous peoples' involvement in renewable energy: exploring reconciliation as relationships of accountability or status quo innocence?", Qualitative Research In Organizations and Management: An International Journal, Vol. 16 Nos 3/4, pp. 636-657. doi: 10.1108/QROM-04-2020-1916.

\section{Further reading}

Mahendru, M., Sharma, G.D. and Hawkins, M. (2020), "Toward a new conceptualization of financial well-being", Journal of Public Affairs. doi: 10.1002/pa.2505. 